\title{
Hurdles of Access and Benefits of Usage for Internet Communication
}

\author{
Kenneth L. Hacker \\ New Mexico State University
}

\author{
Robert Steiner \\ New Mexico State University
}

Studies indicate that the Internet has reached critical mass as a medium of communication and is being used by an increasing number of Americans. At the same time, however, research indicates that there are gaps in how various segments of the American population are using the Internet. To the extent that Internet usage produces tangible benefits, users of Internet communication will have advantages over non-users as will high-users over low-users. This study reports the data analysis of a probability sample of users and non-users of the Internet. Users were asked questions about Internet access variables (called "hurdles"), their frequency of Internet usage, and how much they gain economic, jobs, financial, political, and interpersonal communication benefits from their use of the Internet. Reported data indicate that Internet usage frequency is significantly related to the usage hurdles of skills, opportunities and comfort and that Internet usage frequency is significantly related to the benefits of using the Internet in the areas of jobs, financial information, interpersonal communication, and political information.

It is common today to encounter a great deal of discourse concerning the Internet and what can be obtained from Internet communication. Studies indicate that Internet users are able to gain economic, political, financial, job-related, and communication benefits from

Kenneth L. Hacker (Ph.D., University of Oregon, 1986) is Associate Professor of Communication Studies at New Mexico State University, Las Cruces, NM 88003. Robert Steiner (Ph.D., Oklahoma State University, 1993) is Associate Professor of Experimental Statistics in the Department of Economics at New Mexico State University, Las Cruces, NM 88003. 
using the Net (Anderson, Bikson, Law \& Mitchell, 1995; Bikson \& Panis, 1999; Davis, 1999; Davis \& Owen, 1998; Hacker \& van Dijk 2000; Hill \& Hughes, 1998). However, certain data indicate that various segments of the American population vary in how involved they are with Internet communication (van Dijk, 2000). The latest National Telecommunication and Information and Administration (NTIA) data indicate that groups lagging in Internet usage are older people, handicapped individuals, certain minority groups like African-Americans and Hispanic-Americans, and those who are disadvantaged by low income or education ("Falling Through the Net," 2000). If Internet communication (e-mail, Web sites, discussion groups, etc.) provides tangible benefits for users yet usage is hindered by the access variables we call hurdles, many individuals are likely to lag behind in achieving the advantages of Internet communication.

\section{The Internet and World Wide Web}

Information from the U.S. Department of Commerce indicates that only about 3 million Americans used the Internet in 1994. In 1996, fewer than 40 million people around the world were using the Internet, but by the end of 1997, more than 100 million were online (Margherio, Henry, Cooke, \& Montes, 1998). The Department of Commerce report indicates that traffic on the Internet has doubled every 100 days. While projections are tricky, some observers argue that there may be 1 billion people in the world using the Internet by the year 2002 (Margherio, et al., 1998). Varying estimates of American users in 1999 included estimates of 64 million (Mediamark Research, 1999) and 83 million Americans online (Intelliquest, 1999). The Internet survey clearinghouse, NUA Surveys, claims that the United States Internet population has about 160 million users and that the current world user population is approximately 276 million (NUA, 2000). Individual Internet survey numbers are subject to validity problems, but various trend data can be instructive. Across the surveys, it is clear that the Internet and World Wide Web are being adopted at rates so fast that there are no indications of digital communication diminishing. Internet communication is an attractive new form of communication for those who can afford access and can learn how to use it . Only 20 years ago, there were about 50,000 computers in the entire world, while today that many computers are sold every 10 hours around the world (Gladieux \& Swail, 1999). There were only about 300,000 e-mail users worldwide in 1985. Americans alone today account for about 80 million e-mail addresses (Gladieux \& Swail, 1999). A recent National Public Radio survey indicates that $75 \%$ of Americans under the age of 60 report having used the Internet. The same survey shows that $72 \%$ report that the Internet has improved their lives ("Survey shows wide enthusiasm...," 1999). All statistical descriptions of the Internet as a communication innovation indicate that the Internet has now reached "critical mass," that level of adoption where the technology continues to expand with no likelihood of nonacceptance (Rogers \& Malhotra, 2000).

Katz and Aspden (1997) discovered that there are specific motivations for using and barriers against using the Internet. They found that social and personal development are key motivational factors for using the network as are social and work networking. Personal development includes benefits such as finding desired information. Social development includes increasing the ability to communicate with others by using this new medium. Important barriers to using the new medium include difficulties in using the Internet, insufficient access, and high costs. They also found that social networks are important sources of learning how to use the Internet for new users. In addition to academic studies, 
governmental and commercial survey reports also indicate benefits that can be gained from using the Internet. A recent Roper poll indicated that $71 \%$ of Internet users find useful product information online and $87 \%$ say they use the Internet regularly to communicate with friends or family (Pastore, 1998). Job opportunities that are related to new communication and information technologies are increasing. ("Digital economy 2000," 2000). Employment searches are facilitated by the Internet as job seekers can locate job postings and even apply for work online ("Towards digital eQuality,"1999). Citizen access to government services such as student financial aid applications, legislation, Census forms, government agency reports, contacts with government officials, etc. are facilitated today by Internet communication ("Towards digital eQuality," 1999).

More and more services are becoming available on the Internet and more political communication and actions relevant to a democracy (such as voting) are being planned for net access (Katz \& Aspden, 1997). This suggests that leaving segments of the overall population without net access and skills may lock them out of the digital communication processes that comprise what is known as "digital democracy." These processes include gathering information about candidates from election Web sites, filing documents with local government agencies, and now even voting in presidential election primaries (Davis, 1999; Hacker \& van Dijk, 2000).

According to van Dijk (1999), there are four types of access hurdles that must be passed in order for people to use the Internet. These access hurdles are: 1) degree of basic skills, 2) actual Internet connection - computer plus access to computer networks, 3) comfort with using the Internet, and 4) sufficient opportunities for going online. The van Dijk model is consistent with the research findings of Katz and Aspden (1997). Drawing upon van Dijk's conceptual model, we employed a basic research model to guide the study reported here. The model simply shows the variables that are measured and highlights the possible antecedent conditions for Internet communication (passing the access hurdles) and the benefits obtained from Internet communication (see Figure 1). We not differentiate types of physical access (home, work, schools, etc.) since our focus is usage in general. We also do not address home computer ownership since that presents other research questions and areas of concern.

FIGURE 1

The Research Model

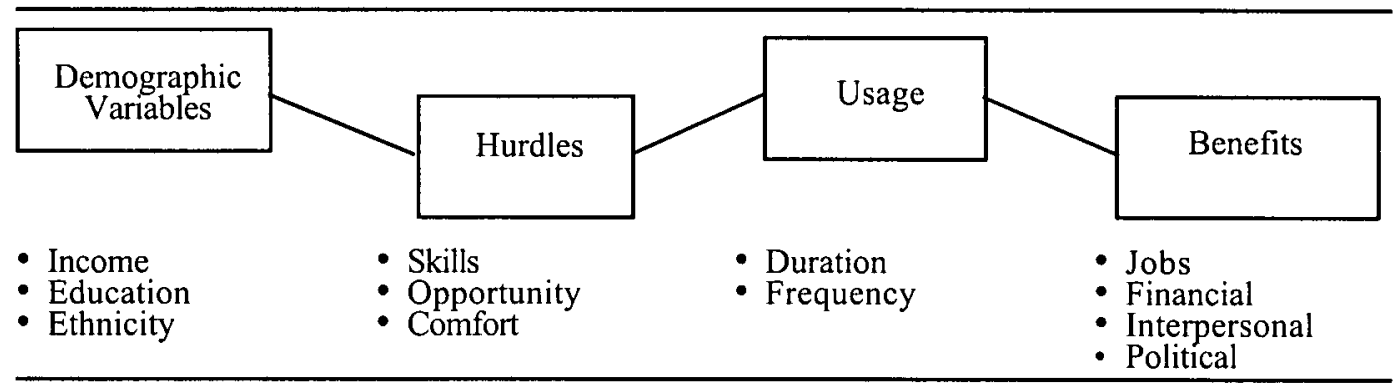

In reviewing the literature, it appears that researchers tend to assume a one-dimensional view of access or what van Dijk (2000) notes as the assumption that access only means physical access to an Internet connection. It also appears that researchers tend to assume that benefits occur and are significant without testing the assumption. The hypotheses tested 
in this study represent three major areas of focus: hurdles or access variables, usage, and benefits variables. These variables are directly related to our research model.

\section{Hypotheses}

It is generally assumed that simply having a connection to the Internet is what makes up access to the Internet. Recent analysis, however, has argued for a multi-faceted accounting of access that accounts for more than machine access (van Dijk, 2000). Studies have shown that simply having access to the Internet does not assure usage of the Internet. For example, when $38 \%$ of Americans said they had Internet access at home, only $24 \%$ reported using it (van Dijk, 2000). One access factor or hurdle is how much skill the potential user has in navigating the Internet (van Dijk, 1999, 2000). Having Internet skills should ease the process of using the Internet for communication. skills.

$\mathrm{H1}$ : Internet usage frequency will be significantly and positively correlated with Internet

The fact that users have skills in using the Internet does not mean that they will use it and those who have more chances or opportunities to participate in online communication will be more likely to do so than those with fewer opportunities (Hoffman \& Novak, 1998; van Dijk, 1999, 2000). Having more occasions to employ the Internet as a medium of communication should increase the likelihood of its usage.

$\mathrm{H} 2$ : Internet usage frequency will be significantly and positively correlated with Internet opportunities.

Some users of the Internet are uncomfortable with the technology. Despite skills and chances to use the Internet, those who do not feel comfortable with it are less likely to use Internet communication than those who are comfortable with it (Katz \& Aspden, 1997; van Dijk, 1999, 2000). Recent polling data indicate that $36 \%$ of Internet non-users believe that online activity is confusing and too difficult and that $54 \%$ believe that it is dangerous (Lenart, 2000). Decreasing anxieties of Internet usage and increasing comfort should encourage usage.

$\mathrm{H} 3$ : Internet usage frequency will be significantly and positively correlated with Internet comfort.

Research has demonstrated that those who use the Internet obtain tangible benefits from their Internet communication such as obtaining information that helps them with employment (Anderson, et al., 1995). If a person finds useful job information from using the Internet, this is likely to increase their usage if the information is useful to them.

H4: Internet usage frequency will be significantly and positively correlated with job benefits gained from Internet usage.

Users of the Internet are able to obtain information that is useful to them in terms of finances (Anderson, et al., 1995). Today, about $20 \%$ of Americans file their federal income taxes over the Internet (Catinat \& Vedel, 2000). More and more people are conducting online transactions involving plane tickets, banking, purchasing, etc. (Neu, Anderson, \& Bikson, 1998). Obtaining useful financial information is likely to encourage Internet usage.

$\mathrm{H} 5$ : Internet usage frequency will be significantly and positively correlated with financial benefits gained from Internet usage.

Research shows that Internet users can increase useful interpersonal communication as with keeping up with family or friends or making new contacts (Anderson, et al., 1995; Parks \& Floyd, 1996; Walther \& Burgoon, 1992). Obtaining interpersonal communication benefits should increase the likelihood of using the Internet. 
H6: Internet usage frequency will be significantly and positively correlated with interpersonal benefits gained from Internet usage.

Studies have indicated that Internet communication can help people obtain political information which is useful for keeping informed or learning about politics (Davis \& Owen, 1998; Tsagarousianou, Tambini, \& Bryan, 1998; van Dijk, 2000). The Office of Management and Budget predicts that the majority of transactions between individuals and the federal government for Social Security benefits, food stamps, and Medicaid help will eventually be done with Internet communication (Bikson \& Panis, 1999). Political interactions that are conducted by telephone or face-to-face contact are increasingly made possible by online communication (Neu, Anderson, \& Bikson, 1998). If a user finds the Internet useful for political communication, that person should be motivated to use it.

H7: Internet usage frequency will be significantly and positively correlated with political benefits gained from Internet usage.

\section{Study Sample}

The research respondents of this study were sampled from the population of a Southwestern municipal area. The total population of this area is approximately 176,000 . To gather the data, a random sample telephone survey was employed. Telephone numbers were generated at random with stratification for prefix areas within the calling district. The questionnaire was administered to address each hypothesis. Likert-type scales were used to gain responses to questions concerning sections of our research model such as hurdles, usage, and benefits of usage. Eleven trained phone interviewers were used to randomly call members of the population. The telephone callers gathered a sample of 319 surveys in a three-day period.

The survey questionnaire asked respondents about how they met the hurdles (access variables) of Internet usage as well as what benefits they felt they received from using the Internet. Hurdles questions concerned issues like having enough skills, access, and opportunities to use the Internet. Benefits variables are perceived job, financial, political, and interpersonal benefits derived from using the Internet. Questions were also asked about ethnicity, income, and education.

For each hurdle and benefit concern, three items were asked. Those which were reliable enough to combine into indices were then used for the analysis. This procedure resulted in three hurdle indices and four benefits indices. All of the hurdles items were correlated sufficiently to allow the creation of three hurdles indices. The Cronbach alpha values were .89 for the skills index, .79 for the opportunities index, and .74 for the comfort index. All of the benefits items were correlated sufficiently to allow the creation of four benefits indices. For the jobs index, the Cronbach alpha for the individual items was .90. The Cronbach alpha for the finance index was .93. For the interpersonal communication index, the Cronbach alpha was .96. For the political information index, the Cronbach alpha was .97. Hypotheses were tested by correlation analysis.

\section{RESULTS}

The probability sampling produced a subject pool that is $55 \%$ Anglo, $36 \%$ Hispanic, $1 \%$ Asian, and the rest African-American, Native American, and others. Regarding education, $19 \%$ of our sample has an education level of either high school education or below and $16 \%$ of the respondents have a graduate degree. For income, $24 \%$ have an income level less than 
$\$ 20,000$ and $19 \%$ have an income of over $\$ 60,000$. For gender, $42 \%$ of the sample is male and $58 \%$ is female. For age, $38 \%$ of the subjects are under $35,29 \%$ are between 35 and 49 , and $33 \%$ are over 50 years of age. For Anglo Americans in the sample, $60 \%$ report using the Internet while 40 report not using the Internet while $47 \%$ of Hispanic Americans report using the Internet while $53 \%$ report not using it. A Chi-square test indicates that these proportions are significantly different $\left(\chi^{2}=4.05, d f=1, p<.05\right)$.

\section{Hypotheses}

Our data indicate that for all of the subjects who are using the Internet, Internet usage frequency is significantly correlated with success in meeting the skills $(p<.01)$ and opportunities $(p<.01)$ and comfort $(p<.01)$ hurdles (see Table 1$)$. Thus, our first three hypotheses were confirmed. We need to note, however, that the correlations, while significant, are low.

TABLE 1

Hurdles by Usage, Spearman Correlation Coefficients

\begin{tabular}{llcl}
\hline & Skills & Opportunities & Comfort \\
\hline Usage & .40 & .48 & .33 \\
$p$ value & $.0001^{* *}$ & $.0001^{* *}$ & $.0001^{* *}$ \\
$n$ & 128 & 128 & 128 \\
\hline
\end{tabular}

Note: ${ }^{* *}$ significant at $p<.01$.

We also found that all four types of benefits (jobs, financial, interpersonal communication, political) are significantly correlated with net use (See Table 2). Thus, hypotheses 4, 5, 6 , and 7 were confirmed. However, we need to note that the correlations, while statistically significant, are low.

TABLE 2

Benefits by Usage, Spearman Correlation Coefficients

\begin{tabular}{llccc}
\hline & Job & Financial & Interpersonal & Political \\
\hline Usage & .28 & .27 & .34 & .33 \\
$p_{n}$ value & $.0007^{* *}$ & $.0009^{* *}$ & $.0001^{* *}$ & $.0001^{* *}$ \\
$n$ & 123 & 123 & 126 & 124 \\
\hline
\end{tabular}

Note: ${ }^{* *}$ significant at $p<.01$.

To take our analysis one step further we tested the associations of hurdles for Internet usage with benefits from such usage. A Spearman correlation analysis indicates that the skills hurdle is significantly but not highly correlated with all four benefits: job $(r=.34, p<.001)$, financial $(r=.18, p<.05)$, interpersonal $(r=.34, p<.001)$, political $(r=.25, p<.01)$. The opportunities hurdle is significantly correlated with the job benefits variable $(r=.24, p<.01)$, the interpersonal communication benefits variable $(r=.36, p<.001)$, and the political benefits variable $(r=.31, p<.001)$, but not with the financial benefit variable $(r=.14, p<.05)$. The comfort hurdle index is significantly correlated with job benefits $(r=.36, p<.001)$, financial benefits $(r=.21$, $p<.05)$, interpersonal benefits $(r=.24, p<.01)$, and political benefits $(r=.25, p<.01)$. 


\section{DISCUSSION}

Overall, our study indicates that Internet usage frequency is significantly related to the usage hurdles of skills, opportunities and comfort. This indicates that potential users of the Internet need much more than machine access to use the Internet for beneficial communication. They also need skills of using the Internet, chances to use it, and freedom from anxieties or what we know as comfort in using this new medium of communication.

We also found that that Internet usage frequency is significantly related to the benefits of using the Internet in the areas of jobs, financial, interpersonal communication, and political information. This suggests that the Internet users obtain tangible benefits from their online communication. In turn, it may be reasonable to argue that one reason for closing Digital Divide gaps is to extend the use of Internet communication to more people since the benefits of such communication are not simply a matter of speculation.

While our probability sample is limited to one geographic area of the American population, it allowed us to test various hypotheses about hurdles and benefits in relation to Internet usage frequency. The results of such testing produce findings which help to identify what people need and what they accomplish with Internet communication. We did not analyze computer ownership in our data analysis and future research should probably do so since anything which makes Internet communication easier to access and use is likely to increase usage of this new medium.

If people with higher Internet usage are more likely to achieve important benefits from usage, we need to know more about what increases usage. If van Dijk (2000) is correct, those citizens who do not gain access and participation in Internet communication will be left out of new interactive experiences that can benefit them. One way to encourage usage is to facilitate meeting the access hurdles we have described. Another is to help potential users to understand the benefits that are possible. A recent $\mathrm{Pew}$ Research Center poll indicated that $51 \%$ of non-users of Internet communication attribute their non-use to not perceiving the loss of anything by their non-use (Lenhart, 2000).

The perception of benefits alone, however, is not likely to be enough in encouraging more people to take advantage of Internet communication. A striking example is that of handicapped people in the United States. While being one of the groups most likely to benefit from such communication (online transactions vs. burdensome travel, etc.), they are only half as likely to have access to the Internet as those who are not handicapped, (NTIA, 2000). Because hurdles and benefits are both significantly related to Internet communication, it may be possible to help more people take advantage of it by helping them overcome the hurdles of comfort, skills, and opportunities while also encouraging them to seek out the benefits related to interpersonal communication, jobs information, financial interaction, and political communication.

\section{REFERENCES}

Anderson, R.H., Bikson, T.K., Law, S.A., \& Mitchell, B.M. (1995). Universal access to e-mail: Feasibility and societal implications. Santa Monica: RAND.

Bikson, T. K., \& Panis, C. W. A. (1999). Citizens, Computers, and Connectivity. Santa Monica, CA: RAND.

Catinat, M., \& Vedel, T. (2000). Public policies for digital democracy. In Hacker, K. and van Dijk, J. (Eds.). Digital Democracy: Issues of Theory and Practice. (pp. 184208). London: Sage.

Davis, R. (1999). The web of politics. New York: Oxford University Press. 
Davis, R., \& Owen, D. (1998). New media and american politics. New York: Oxford University Press.

"Digital economy 2000," (2000). Washington, DC: Department of Commerce.

"Falling through the net." (1995). Available: http://www.ntia.doc.gov/ntiahome/ fallingthru.html.

"Falling Through the Net II: New Data on the Digital Divide" (1998). Available: http://www.ntia.doc.gov/ntiahome/net2http://www.ntia.doc.gov/ntiahome/ fallingthru.html

"Falling Through the Net: Defining the Digital Divide" (1999). Available: http:// www.ntia.doc.gov/ntiahome/fttn99/contents.html

"Falling Throught the Net:Toward Digital Inclusion": (2000). Available: http:// www.ntia.doc.gov/ntiahome/fttn00/contents 00 .html

Gladieieux, L. E., \& Swail, W. S. (1999). The Virtual University and Educational Opportunity. Washington, DC: The College Board.

Hacker, K., \& van Dijk, J. (2000). Digital democracy: issues of theory and practice. London: Sage.

Hill, K., \& Hughes, J. (1998). Cyberpolitics: Citizen activism in the age of the Internet. New York: Rowman and Littlefield Publishers.

Hoffman, D. \& Novak, T. (1998). Bridging the digital divide on the Internet. Science, pp. 390-391.

Katz, J., \& Aspden, P. (1997). Motivations for and Barriers to Internet Usage: Results of a National Public Opinion Survey. Internet Research, 7, 170-188.

Lenhart. A. (2000). Who's not online: $57 \%$ of Those Without Internet Access Say They Do Not Plan To Log On. Washington, DC: Pew Internet and American Life Project.

Neu, C. R., Anderson, R., \& Bikson, T. (1998). E-mail Communication Between Government and Citizens. Santa Monica, CA: RAND.

NUA Surveys.(2000). How many online? Available:http://www.nua.ie/surveys/ how_many_online/index.html

Margherio, L., Henry, D., Cooke, S., \& Montes, S. (1998). The emerging digital economy. Washington, DC: United States Chamber of Commerce.

Parks, M. \& Floyd, K. (1996). Making friends in cyberspace. Journal of Communication, 46, 80-97.

Pastore, M. (1998). "Internet becoming necessity to users." http:// www.cyberatlas.com.

Rogers, E., \& Malhotra, S. (2000). Computers as communication: The rise of digital democracy. In Hacker, K. and van Dijk, J. (Eds.). Digital democracy: issues of theory and practice. (pp. 10-29). London: Sage.

"Survey shows widespread enthusiasm for technology." (1999). National Public Radio. Available online: http://www.npr.org/programs/specials/poll/technology.

"Towards digital eQuality,"1999. Washington, DC: Department of Commerce.

Tsagarousianou, R., Tambini, D., \& Bryan, C. (Eds.). (1998). Cyberdemocracy: technology, ciites, and civic networks. London: Routledge.

van Dijk, J., \& Hacker, K. (June, 2000). The Digital Divide as a complex and dynamic phenomenon. Paper presented to the International Communication Association, Aculpulco, Mexico. 
van Dijk, J. (2000). Widening information gaps and policies of prevention. In Hacker, K., \& van Dijk, J. (Eds.). Digital democracy: Issues of theory and practice. (pp. 166-183). London: Sage.

van Dijk, J. (1999). The network society. London: Sage.

Walther, J. \& Burgoon, J. (1992). Relational communication in computer-mediated interaction. Human Communication Research, 19, 50-88. 
Copyright of Communication Research Reports is the property of Eastern Communication Association and its content may not be copied or emailed to multiple sites or posted to a listserv without the copyright holder's express written permission. However, users may print, download, or email articles for individual use. 